\title{
1. Introduction: reshaping regional policy in Korea Sang-Chuel Choe
}

\section{REGIONS IN THE KOREAN CONTEXT}

Korea is well known for remarkable economic success over the past halfcentury. Comparing with the 1960s, gross domestic product (GDP) per capita has risen more than 200 times, and exports have increased over 1000 times. Korea became an OECD member country in the mid-1990s, hosted the 1988 Olympic Games, 2002 World Cup, and is going to host the G20 summit in November 2010. Now, in the twenty-first century, Korea is ranked as the 14th-largest economy and is geared up to become an even more active actor in the global economy.

Along with this growth story, the national territory and regions in Korea have been rapidly reorganized and reshaped. From a traditional agricultural and rural society up to the 1960s, Korea is now one of the most urbanized and industrialized societies in the world. Roads and railroads, logistic ports, international airports, industrial complexes, nuclear power plants and many other facilities have been constructed while more than 90 percent of South Koreans now live in urbanized areas.

In spite of these accomplishments, Korea is still struggling for successful regional development. Entering the twenty-first century, Koreans have focused on local developmental rather than national issues, quality of life more than economic issues, and local and regional governance rather than centralized administrative issues. Such a shift in concern is derived from the growth in mature civil consciousness during the decades of economic growth and from a cumulative desire for self-reliant development at the community and regional levels.

In recent years, balancing development in the South Korean territory has become a more important and challenging policy issue. While the national economy and the Capital Region seem to show promising prosperity, a large portion of Korea still suffers from regional problems such as population decline, lack of vitality, loss of competitive potential, deterioration of settlement conditions, and so on. That is why the Korean 
government now places a greater emphasis on regional development policies, especially since 2008, when President Lee Myung-Bak came into power, and the Korean government established a new scheme for regional development policies. Policy principles include interregional cooperation, competition and decentralization. We call this new policy framework the reshaping of regional policy. Against this backdrop, I am going to review how Korea deals with regional development issues, how the Korean government is implementing new regional policies, and what challenges we are facing.

\section{PCRD AND THE SHIFTING PARADIGM OF REGIONAL POLICY}

The region is a comprehensive and complex arena where people live and where government and business carry out diverse activities. Local governments as well as the central government have a responsibility to use and develop the regions and national territory effectively, enhance their competitiveness and preserve the land and the environment. In Korea, a small and densely populated territory, an effective and systematic development of its regions is imperative. Korea in the twentieth century was focused on national economic growth. However, the twenty-first century can be an era of rediscovery of regions and reshaping regional policy.

The institutional setting for regional policy in Korea may be best explained by the establishment of the Presidential Committee on Regional Development (PCRD). As a region is a very comprehensive mixture of land, nature, people, culture and economy, so must be regional development policy. A single agency where the mission is specialized in a specific sector cannot cope with all the regional issues. Hence, the Korean government established an agency through which all policies and administrative measures for regional development can be coordinated and synthesized. Thus, the PCRD is orchestrating regional policies of government agencies such as the Ministry of Knowledge Economy; the Ministry of Strategy and Finance; the Ministry of Education, Science and Technology Development; the Ministry of Public Administration and Security; the Ministry of Culture, Sports and Tourism; the Ministry of Food, Agriculture, Forestry and Fisheries; the Ministry for Health, Welfare and Family Affairs; the Ministry of Environment; and the Ministry of Land, Transport and Maritime Affairs. In addition, the PCRD has prominent experts and scholars among its members.

The global financial crisis that erupted in 2008 has drastically changed the global and domestic economic environment. Accordingly, the Korean 
government clearly has altered its philosophy for regional development policy. It could be called a paradigm shift in regional policy.

In the past three decades, the geographical boundaries of regions have been enlarged and cooperation beyond regional boundaries has been enlarged. Interregional cooperation to achieve more economies of scale and connectivity has been extended even across the national border. This trend is consistent with worldwide concerns about mega-city regions and regional competitiveness, suggesting that competitive regions such as major metropolitan areas (or mega-city regions) will play a greater role in the global economy rather than nation states. It is reasonable to suggest that advanced nations everywhere promote national development via selective concentration around global mega-city regions.

Many countries have adopted larger spatial units for regional planning and policy, such as the United Kingdom's nine Regional Development Agencies, France's 22 regions, and the Japanese eight mega-local regions. After the establishment of the European Union, European countries with the assistance of the European Council launched various initiatives and carried out many cross-border cooperative projects.

Under the current global economic structure, national borders cannot be barriers that hinder the mobility of factors of production such as capital, labor and technology. Because of the development of information technology, economic networks can be created ubiquitously across the globe. Thus, it is imperative for a nation to pursue 'open regions' that facilitate the maximum transfer of resources and capital. It is then inevitable for the geographical unit of regional policy to become larger.

It is difficult for 'closed regions' to maintain the current level of development, not to mention sustainable development. In order for a region with limited resources and capacity to become a larger economic region, networking with other regions is essential. Regions which are geographically dispersed but functionally connected can reap the synergistic benefits of cooperation. This logic in principle can be extended further to larger geographical scales covering transborder spaces. In other words, a region cooperating with others can create more viable and competitive economic regions.

In the twenty-first century global competition has been intensified, centering on global mega-regions, with the implication that regional policies will play a more important role. All countries are now striving to nurture green growth engines, such as eco-friendly industries and renewable energy strategies. Regional policies build a spatial foundation for each region to attract and develop new industries, while ensuring their effectiveness and competitiveness. Parallel with setting the larger spatial units for regional development policy, strategies for regional competitiveness 
and the enhancement of growth potential become the focus of policy attention.

Another important factor in the paradigm shift of regional policy is localization and decentralization. Main territorial policy goals in Korea in the 1980s addressed the widening disparity among regions and the concentration of population in the Capital Region. For example, the Second Comprehensive National Territorial Plan (1981-90) had four objectives: inducing the population to move to provincial areas; searching out development potential nationwide; upgrading citizens' welfare standards; and preserving the natural environment across the nation. In particular, various measures including the Capital Region Readjustment Planning Act were implemented to reduce the concentration of population and industry in the Capital Region. In the 2000s, the Korean government tried to empower local governments by relocating central administration functions and public organizations from the Capital Region to the provinces and attracting businesses there. However, these efforts did not bring about substantial results. Recognizing these shortcomings, the Lee MyungBak government altered its policy direction from declaratory 'balanced regional development' to 'regional specialization and competition' that attempts to implement effective self-reliant localization policies.

\section{CURRENT REGIONAL POLICY ISSUES IN KOREA}

Korea has faced social conflicts arising from the concentration of resources and economic activities in the Seoul Metropolitan Region (Capital Region). About 49 percent of the total Korean population is concentrated in the Capital Region, which covers only 12 percent of the national territory. Apart from population, cultural and social resources, quality job opportunities and high-quality services are also concentrated in the Capital Region. Such a heavy concentration, in spite of agglomeration benefits, not only increases congestion costs but also aggravates the social divide between the Capital Region and the rest of the country.

Accordingly, regional disparities have become the main issue of regional policy. Although the gap in gross regional domestic product (GRDP) among regions in Korea has been one of the smallest among the OECD countries, the demand from the non-Capital regions for better living conditions such as employment, income, social infrastructure, education, culture and welfare facilities have risen significantly.

Another problem is the weak global competitiveness of the Korean regions when compared internationally, and it deserves policy attention. The Capital Region is the third-largest region in terms of population, and 
ranks ninth in terms of the size of GRDP among the 324 regions of OECD countries. However, its rank for per capita GRDP is quite low. This suggests that the Capital Region needs to improve its global competitiveness based on its scale. Korea's second-largest region, the Dongnam Region located in southeast Korea, ranks 29th in terms of population and 49th in terms of GRDP but 81st in terms of per capita GRDP. This region (as well as other regions in South Korea) requires substantial improvement in productivity to become more competitive among regions.

In 2003, the former government (the administration of President Roh Mu-Hyun) established the Presidential Committee on Balanced National Development (reorganized as the PCRD in 2008) in order to deal with regional development issues. The Roh government emphasized balanced national development with a variety of policy measures including the relocation of the Capital, the dispersal program of government offices, the designation of enterprise zones, and other policies. The expected results of the balanced national development policy did not materialize in spite of government investments in several key projects. Despite the possible normative values of balanced national development, the strategies adopted by the previous administration did not pay sufficient attention to the practicality and effectiveness of regional policies.

The balanced national development policy lacked 'balance' in the sense that it simply pursued regional equity per se. If global competitiveness is a key factor for regions to survive in the globalization era, it should have been fully incorporated into regional policies in addition to the longstanding goal of domestic regional balance. Indeed, most countries in Europe and North America are actively pursuing the reorganization of economic regions to achieve global competitiveness. It is an excellent time for Korea to reshape its regional policy by using the momentum arising from globalization and decentralization.

The relocation of the Capital, the dispersal program of government offices, and regional strategic industry projects which were initiated by the balanced national development policy did not meet people's expectations. Unfortunately, these projects did not produce the intended results because of their impracticability. The simultaneous launching of these development projects, involving a large-scale compensation for land, resulted however in a significant rise in land prices in Korea. Balanced national development policy, in spite of its good intentions, did not take advantage of the momentum of decentralization. A participatory approach in the policymaking process was encouraged but ended up with the usual top-down approach and a politically negotiated allocation of resources between regions. As a result, local governments became more dependent on the central government's decisions for resource allocation among regions. 
Thus, interregional rivalry and conflicts in resource allocation intensified. Furthermore, the participatory approach inadvertently promoted competition among central ministries and agencies so that too many overlapping regional development projects were initiated and implemented.

The issue of deregulation was sidelined for the sake of balanced national development policy. Pro-growth forces, emphasizing Korea's global competitiveness, demanded the removal of regulations imposed on the Capital Region. The solution sought in balanced national development policy was to develop the non-Capital region first and deregulate the Capital Region later. However, the result was unsatisfactory to both pro-growth and pro-balance forces. The conflicts between the Capital and the non-Capital regions were consequently aggravated.

\section{RESHAPING REGIONAL POLICY AFTER 2008}

In 2008, the Lee Myung-Bak government launched the PCRD to set up new regional development policies. The PCRD faces three major challenges. The first challenge is the potential and imminent impact of the process of globalization on regional development. Globalization is transforming cities and regions around the world. The global financial crisis beginning in 2008, unanticipated by policy-makers and experts alike, has caused immediate and pervasive impacts on regional economies. Although variations exist among countries and regions, a few commonalities are apparent with regard to the spatial consequences of the crisis. They are epitomized by highly concentrated development in a limited number of mega-city regions that aggravate regional disparities among mega-regions and smaller regions. However, the formation of the mega-city region is a common phenomenon to gain a competitive edge in this era of unlimited and borderless competition among nations and regions. Populist and domestic-oriented balanced regional development policies undertaken by the former government need to be redefined. As a result, the incumbent government of President Lee Myung-bak has introduced a new three-tiered spatial scheme of the Supraeconomic Region, Economic Region and Local Area development.

Secondly, the last decade has also seen an unprecedented momentum towards the decentralization of power and responsibilities in Korea. Paradoxically, decentralization has been happening at the same time as globalization. A gap between rising local demands asking for an equal share of national resources and regional potential has become a serious political issue which tends to impair national and regional competitiveness. The key task is how to achieve a national consensus between balanced regional development and regional competitiveness. 


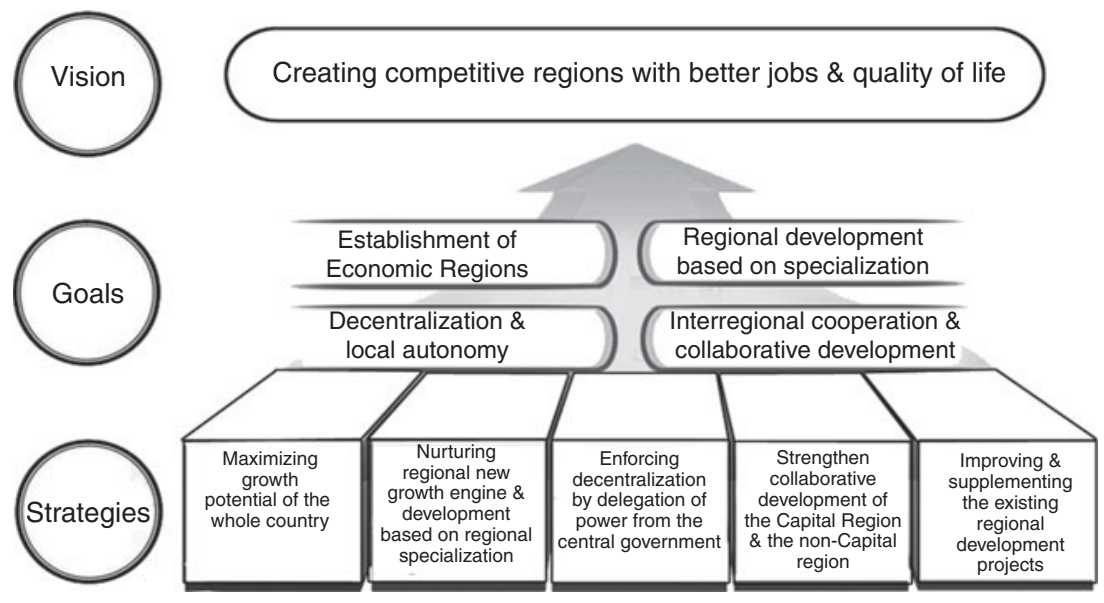

Figure 1.1 Goals and strategies of the new regional policy

The third challenge is how to institutionalize a regional development system within a given political and administrative structure. Departmentalism in the central government, volatile central-local relationships and contested stakeholders (including civil organizations) need to be brought into the process of planning and implementation.

Global climate change adds another challenge to regional development. The Korean government is strongly engaged with the global mandate of climate change and green growth as one of the most important national agendas. This new agenda item must be addressed in regional policies.

To tackle these challenges, the PCRD is geared up to advance new regional development policy with five key strategies (Figure 1.1). First, the new policy frame is centered on the three-tiered approach along with different geographical scales: (1) the Economic Region scheme is to regroup uppertier local governments (16 metropolises and provinces) into seven Economic Regions; (2) the Local Area scheme is to provide quality-of-life services and income-earning opportunities for all of the residents in lower-tier local governments (163 cities and counties); and (3) The Supra-economic Region scheme is to create four Supra-economic Regions along the coastline or the national border with an additional Inland Supra-economic Region for the promotion of cross-economic region and cross-border cooperation. Details on the three-tiered approach will be explained below.

Second, the government will nurture new regional growth engines and promote regional development based on specialization. More specifically, selected strategic industries for each economic region will be fostered to improve global competitiveness. Synergistic effects of diverse strategic 
industries will also be pursued through boosting interregional linkages, cooperation and convergence.

Third, in order to enforce decentralization by delegating power from the central government to local governments, the following tasks need to be carried out: the devolution of central government's regional agencies; the redistribution of taxes between central and local governments; the integration of myriad national subsidies into block grants for regional development; and the transfer of development authority to local governments for better planning and implementation.

Fourth, the symbiotic development of the Capital Region and the nonCapital region can be pursued through diverse channels. They include a stepwise deregulation of the Capital Region concurrent with regional development in the non-Capital region; the transfer of capital gains earned by developing land in the Capital Region to local governments in the non-Capital regions; reducing regulations and improving the institutional environment to reinvigorate the regional economy; and augmenting government support to attract businesses and promote investment into the non-Capital region.

Fifth, existing regional projects inherited from the former administration will be continued. For example, the dispersal program of government offices will contribute to making growth hubs in the Economic Regions. The relocation of the Capital will be revisited so as to build a city for self-sustained development. Incentive measures such as tax exemptions and low-priced land can be used to attract universities and high-tech business. Enterprise zones will also be encouraged to establish a base for self-sustained growth by strengthening support for the developers and on-site firms.

\section{THE SCHEME FOR ECONOMIC REGIONS}

Economic Regions (ERs) have been drawn up in consideration of the regions' economic and industrial structure, historical continuity and cultural homogeneity. This scheme is designed to improve regional competitiveness via interconnection and cooperation among smaller, individual regions. The rescaling was made on the basis of population size, industrial agglomeration, location, infrastructure, historical and cultural characteristics, and local administration and sentiment. The nation's 16 metropolises and provinces were grouped into five ERs (the Capital Region, Chungcheong Region, Honam Region, Daegyeong Region and Dongnam Region), each with more than 5 million population, plus two relatively isolated special ERs (Gangwon Region and Jeju Region) with about 1 million population each. 


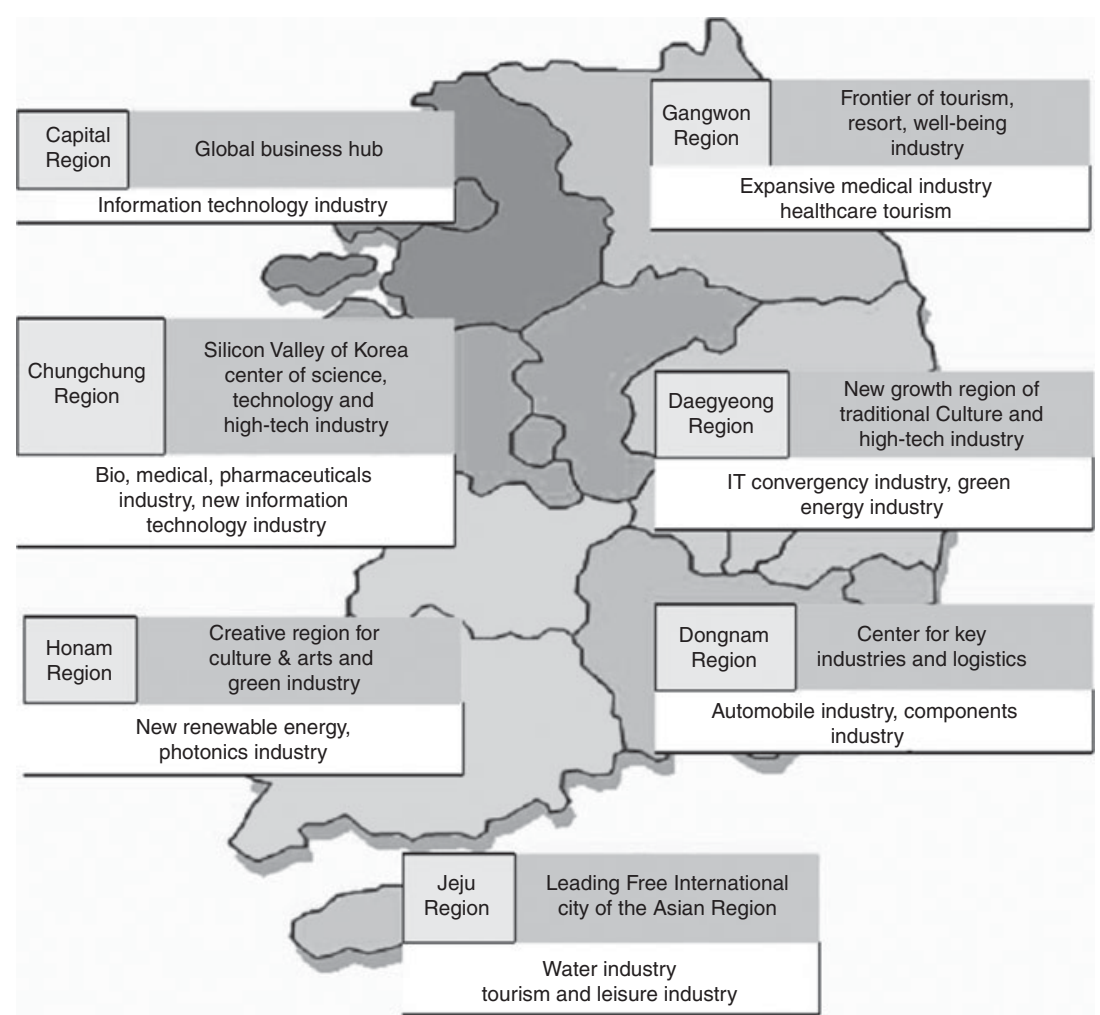

Figure 1.2 5+2 Economic Regions and their leading industries

The ERs are the basic unit upon which to build the nation's global competitiveness. This scheme is designed for integrated regional development at the mega-region scale by encouraging cooperation and coordination among local governments within each ER. It is a clear departure from the past regional development policy framed by the administrative units of metropolises and provinces.

The promotion of new growth engine industries and other projects critical for the nation's future are now being carried out at the ER level. The policy is designed to build multiple regional economies comparable to the Capital Region by making each ER have its own leading industries to generate growth and jobs as well as its own core universities to enhance human capital and research capability. The three key strategies of the ERs are: (1) the priority provision of 30 infrastructure projects; (2) the selective investment of two leading industries for each ER as shown in Figure 1.2; and (3) the designation of hub universities to match up with the demands 
of the leading industries. In the early phase, the central government will lead regional development by pilot projects so as to provide development momentum in each ER. Each ER in close consultation with the central government will also draw up its own vision for development.

The government set the institutional framework for this new scheme by revising the Special Act on Balanced National Development ('the Special Act' hereafter) in April 2009. With this Act, the five-year National Plan for Regional Development is being formulated. Consisting of both the Sectoral Development Plan and the Economic Region Development Plan, this is a comprehensive national planning scheme for enhancing regional competitiveness and promoting cooperative networking among regions. In December 2009, the draft of the Plan passed the Cabinet meeting.

The Economic Region Development Plan for the seven ERs is also being formulated. For the implementation of the Economic Region policy and programs, the Economic Region Development Committee (ERDC) as a standing and independent agency, which is somewhat comparable to England's Regional Development Agency (RDA) and the French 'Region', was established for each ER. The Economic Region Development Plan is to be drawn up every five years by the head of each ERDC in consultation with the heads of related central administrative agencies. It is a comprehensive strategic plan to enhance the global competitiveness of ERs. It includes the fostering of regional industry, cultivating human resources, advancing science and technology, building regional growth poles, providing and maintaining social overhead capital, and boosting regional tourism as well as cultural activities. Currently, regional plans are being prepared and the annual action plans are being drafted by each ERDC.

\section{THE SCHEME FOR LOCAL AREAS}

'Local Area' here corresponds to the space of residents' everyday life and is the basic unit for policies to improve living standards. As such, this scheme aims at providing stable jobs and basic services, especially to localities remote from the major developed metropolitan regions. A total of 163 cities and counties, excluding wards in Seoul and other metropolises, were designated as Local Areas (Figure 1.3). They accounted for 54 percent of the nation's population as of 2007. Population in rural Local Areas (agricultural, fishing and mountain-area villages) declined by 14.7 percent between 1995 and 2007. In these places, the percentage of the population who are 65 years or older has reached 21.6 percent but residents there still suffer from poor medical services, water supply and drainage, among other problems. 


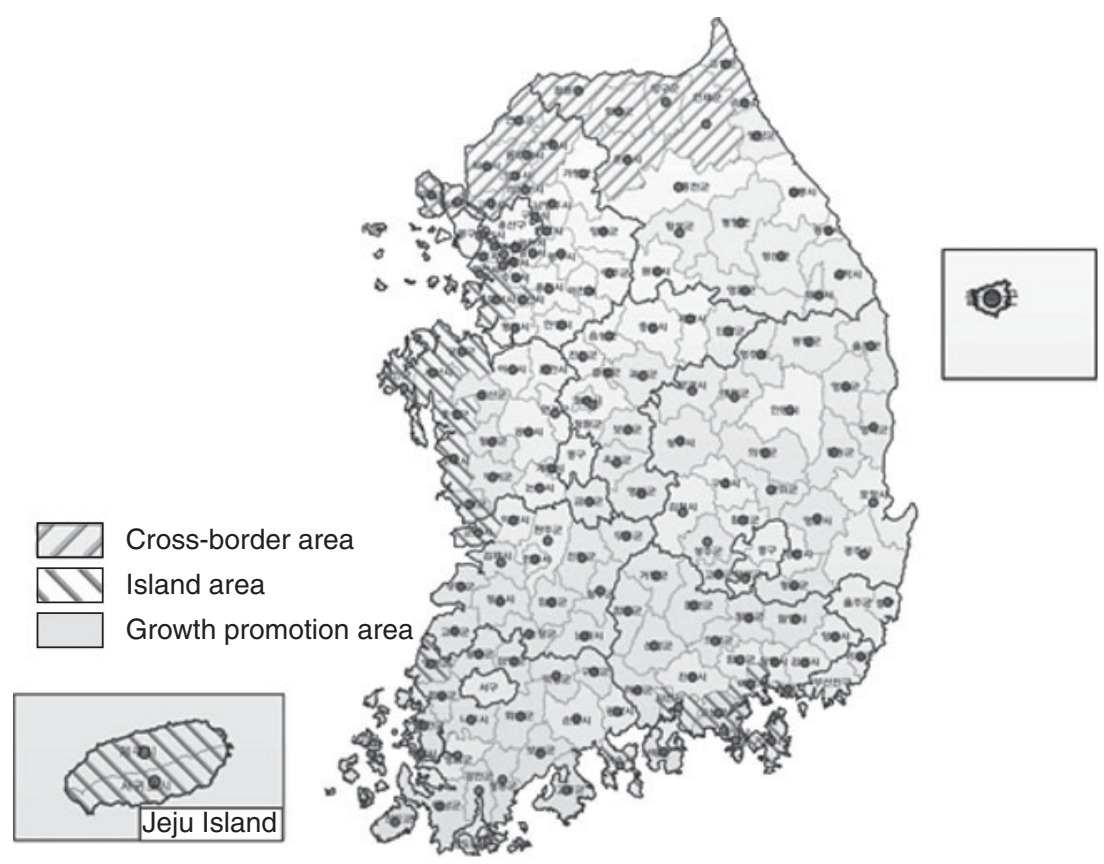

Figure 1.3 163 Local Areas in Korea

The scheme envisions 'the creation of areas, where people want to achieve their dreams' by ensuring stable jobs and incomes and accommodating everyday needs. In order to achieve this vision, the plan calls for both local government efforts to foster their growth potential, and central government support to guarantee minimum living conditions. It seeks to provide development directions for rural villages and smaller provincial cities that have been overlooked in the nation's metropolitan-focused development policies.

The idea of Local Area development is propelled by the formulation of the Local Area Development Plans. Although not mandatory, over 90 percent of the 163 areas are making their own development plans. By providing technical support and on-the-job training for local planners, the PCRD is working closely with municipal governments.

With regard to the quality of life and settlement conditions in Local Areas, the PCRD set ten major tasks for both central and local governments. These tasks are grouped into 'bottom-up endogenous development strategies' and 'top-down exogenous development strategies', and the details are as follows.

The endogenous development strategies include: (1) make new growth 
engines by using locally endowed resources; (2) produce high-value-added goods by developing local industries; (3) conduct proactive place marketing based on historical and cultural heritage; (4) build a collaborative system by networking existing community leaders and organizations and using the trained creative class; and (5) implement voluntary integration of administrative divisions and collaborate with each other on a regional scale.

The exogenous development strategies include: (1) improve public services in health and welfare, especially in underdeveloped communities and among disadvantaged families; (2) improve cultural facilities and programs for local residents; (3) strengthen educational competitiveness in the non-Capital regions; (4) improve basic living conditions including housing, job opportunities and water services; and (5) implement local green growth programs.

\section{THE SCHEME FOR SUPRA-ECONOMIC REGIONS}

This scheme has two purposes: one is to deal with the global dimension of regional development in a peninsula country in Northeast Asia and the other is to promote coordinated development between and among ERs. It is envisioned as three coastal belts and one border belt (East Coast Energy-Tourism Belt, West Coast Industrial Belt, South Coast Sun Belt and the North-South Border Belt along the demilitarized zone - DMZ) and an additional Inland Specialized Belt (Figure 1.4).

The main purpose of this scheme is to facilitate interconnected development of the ERs internally as well as internationally. Each Supra-economic Region will enrich growth potential through cooperation with other regions in Korea and neighboring countries around the Korean peninsula. The government intends to support building supra-regional infrastructure such as transport networks and industrial clusters to facilitate both the interregional and international connectedness of the ERs. The regional assets and resources available in each Supra-economic Region will be jointly used to cultivate a new growth potential with neighboring regions in China, Japan and Russia.

The central government has formulated a Comprehensive Plan for the Supra-economic Regions based on a draft presented to the President in December 2009. The primary purpose of the Supra-economic Region is to transform the coastal and border areas into the new open development corridors of the future. In addition, Inland Specialized Belts, of which proposals were made by regional entities, are being considered to be designated. According to the Special Act, the PCRD is responsible for their designation. 


\author{
$\triangleright$ VISION \\ Central Eco-Peace Belt of the Korean \\ Peninsula
}

\section{$\triangleright$ VISION}

Gold Belt

of Knowledge-based High-tech Industry

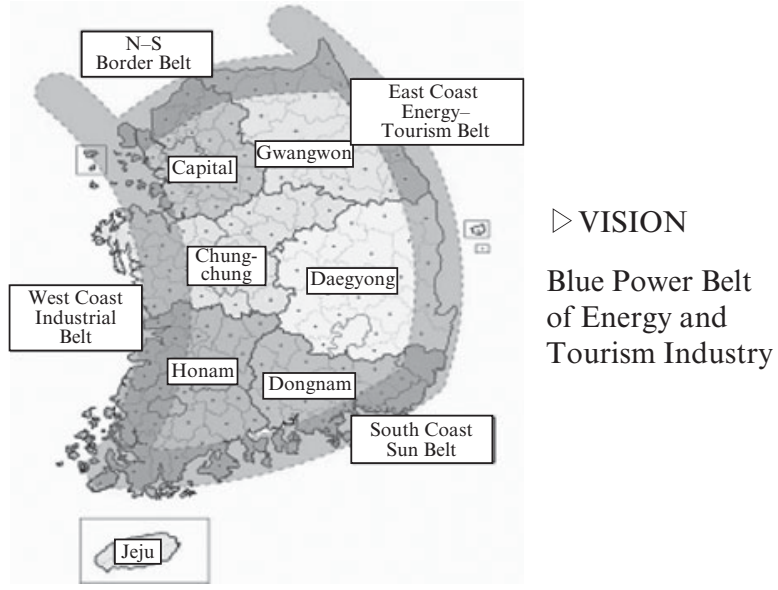

$\triangleright$ VISION

New Hub of Economy, Logistics, and Recreation

Note: Inland Belts have not been designated yet.

\title{
Figure 1.4 Supra-economic Regions
}

Five promotion strategies are devised to bring the Supra-economic Regions to fruition. First, to establish a foundation for cross-border cooperation in Northeast Asia, the government will construct an Integrated Trans-Eurasian Transportation Network of roads, railways, airports and ports, which will connect the Northeast Asian region with the Eurasian continent. The government will also facilitate economic exchanges and cooperation between cities on the West Coast Rim, East Coast Rim and in the Trans-Pacific Region. Second, to encourage a win-win development and functional connection within the Supra-economic Regions, the government will build interregional infrastructure networks including main transportation and logistic networks, which connect the north with the south, and the west with the east, in both the medium and the long run. Third, the government will foster world-class industrial clusters focusing on key manufacturing industries, logistics and green industries 
such as renewable energy. Fourth, based on nationwide common natural resources, which lie across the Supra-economic Regions such as the Four Rivers, the Baekdu mountain range and historical cultural heritage sites, the government will launch cooperative regional development projects in the culture, tourism and ecological sectors. And fifth, along with the improvement of relations between North and South Korea, the government will lay the spatial foundation for the reunification era by initiating exchanges and cooperative projects in the industry, tourism, ecological and environment sectors in the border zones.

In relation to these five strategies, the government will establish the Supra-economic Regional Development Scheme in detail and will promote the amendments of relevant laws and regulations to drive the scheme forward.

\section{FINANCING AND INSTITUTIONAL ARRANGEMENTS}

As briefly explained above, Korea's regional development policy incorporates the global trend of emerging mega-regions and decentralization. The policy intends to achieve global competitiveness by territorial rescaling, and self-sustainable regional development by specialization. At the heart of the new paradigm of regional development policy is the three-tiered approach or territorial development schemes, which center on seven Economic Regions linked with and complemented by the Local Areas and the Supra-economic Regions.

To make a reshaped regional policy work, the government announced a Five-Year Regional Development Plan in September 2009, elaborating on the three-tiered approach and specifying future regional tasks. It is a comprehensive legal framework and a mid-term action plan linked to local budgets for implementation between 2009 and 2013. The blueprint is based on the central government's plans for Economic Regions, Local Areas and Supra-economic Regions. To facilitate financial decentralization and the local discretion of regional development, the government newly introduced a local consumption tax and local income tax in 2009.

The government has also mapped out concrete investment plans. About 52.4 trillion won have been earmarked for the seven Economic Regions for five years until 2013 in order to build key infrastructure projects, strategic industries and human capital. It is part of a 126.4 trillion won investment in regional development during the same period. Fifty-six percent of the total investment or 71.2 trillion won will come from government coffers, while 24 percent or 30.9 trillion won will be financed by the private sector. 
This investment in regional development is expected to create 1.9 million new jobs.

Such a financial plan is feasible under the Special Act, which was significantly revised in April 2009. Designed to facilitate sustainable regional development, the Special Act legitimates the activities of the PCRD, which is in charge of national policy for regional development. It aims at strengthening regional competitiveness and improving the quality of life by region-specific customized development, and enhancing networking and cooperation among regions. The Special Act has created a Special Account for Regional Development. The main target of this Special Account is to provide stable financial support for regional development plans. Among national subsidies, those earmarked for regional development are assembled into this special grant. It consists of three parts: the Economic Region Development Sub-account, the Local Development Sub-account and the Special Account for the Jeju Special Autonomous Island.

In the operation of the Local Development Sub-account, the Special Act introduces block grants especially for local government budgeting. Central government grants are divided into two: one category is the general grants left to local government discretion and the other is for special-purpose grants specified by the central government. Generally, central government block grants have intermediate characteristics, because they are considered, on the one hand, as earmarked grants in terms of their use within the block grants and, on the other hand, as general grants with local discretion. There were more than 200 local development projects in the past. The introduction of the block grant system by the central government has been simplified into 24 categories.

All the regional plans and development programs were designed by mid-2010 and their implementation has recently begun. However, further institutional arrangements are required to ensure proper performance assessments. The Special Act lays down rules on how to assess the outcomes of regional development plans and projects using national budgets and resources. The primary aim of assessments is to evaluate the quality and achievements of projects. The significantly reshaped regional development policy in Korea combines both financing resources and institutional devices. The core is the Special Act. Nevertheless, there are still shortcomings, but both the Korean government and the PCRD will work towards more efficient implementation. 


\section{CHALLENGES AHEAD}

The rationale of regional development policy lies in the enhancement of regional economies and the enrichment of life through concrete plans and programs. In charge of Korean regional development policy, the PCRD aims to improve living standards in every region. The Committee believes that regional competitiveness will be strengthened when regions are allowed to mobilize resources and to develop plans by themselves. The central government plays a facilitator's role by providing financial and technical support.

Most countries in the world embrace both globalization and localization. Given accelerating globalization, national competitiveness increasingly depends on its regions. Developed countries have been adopting larger spatial units as the object of regional policy, and promoting cross-border cooperation to strengthen regional competitiveness. In these countries, micro-regionalism bound by administrative units is replaced by new regionalism in pursuit of the economies of scale and agglomeration.

Recognizing fully the implications of deepening globalization and localization trends for Korean regions, the central government launched a new regional development initiative in 2008. In particular, the PCRD and related ministries and agencies have worked to make better regional policy. Several challenges lie ahead, however. They include: how to devise effective and practical mechanisms to make ERs globally competitive; how to entice regional and local administrative units into effective interregional cooperation networks within and outside the national border; and how to raise local capacity for self-sustainable development. In addition, the policy needs to find a solution to resolve the long-standing issue of a regional divide between the Capital Region and the non-Capital regions.

To refine Korea's regional policy further, the PCRD would like to discuss best practice with experts both in Korea and abroad. The Committee would also like to learn about new trends and emerging policy issues from the experiences of other countries. It intends to establish a global network of academics and policy-makers for regional development. Finally, the PCRD hopes that Korea's efforts in reshaping regional policy will benefit not only Korea but also other countries contemplating regional development policies in this era of great transformation. 